\title{
Performance Analysis of an Innovative ORC-based Micro-scale CCHP System under Lebanese Conditions
}

\author{
M. JRADI ${ }^{1 *}$, S.B. RIFFAT ${ }^{2}$ \\ ${ }^{1}$ Center for Energy Informatics, The Mærsk Mc-Kinney Moller Institute, University of Southern Denmark, 5230 Odense \\ M, Denmark \\ ${ }^{2}$ Institute of Building Technology \& Institute of Sustainable Energy, Faculty of Engineering, University of Nottingham, \\ Nottingham, UK \\ *Corresponding Author Email: $\underline{\text { mjr@mmmi.sdu.dk }}$
}

Received 10 December 2018, Accepted 06 May 2019

\begin{abstract}
Considering the high demand for cooling, heating and electricity and with more than 300 annual sunny days, an innovative hybrid biomass-solar driven micro-scale tri-generation system is proposed to provide cooling, heating and electricity under Lebanese conditions. The system comprises an organic Rankine cycle-based combined heat and power unit, a liquid desiccant dehumidification unit and a dew point evaporative cooling unit. A complete technical, economic and environmental assessment of the tri-generation system is performed to assess its applicability and feasibility. Employing a $2 \mathrm{kWe}$ ORC-based CHP unit, the useful heat output ranges between 4.2 and $11.75 \mathrm{~kW}$, with an electric power capacity between 0.7 and $1.92 \mathrm{~kW}$. The maximum hourly cooling capacity delivered by the coupled cooling and dehumidification system is attained in August with $8.7 \mathrm{~kW}$. The tri-generation system allows annual savings of 8225 USD on the heating bill, 960 USD on the electricity bill and 950 USD on the cooling bill compared to conventional production technologies. In addition, the $\mathrm{CO}_{2}$ emissions reduction ranges between 3.1 tons in June and 9.2 tons in March. The results of this study demonstrate the large potential of using such tri-generation systems under the Lebanese conditions compared to the conventional separate energy production technologies.
\end{abstract}

Keywords: Micro-scale tri-generation system, Organic Rankine cycle; Evaporative cooling; Liquid desiccant dehumidification; Techno-economic and environmental analysis.

\section{Introduction}

Achieving a secure and reliable energy production and supply sector is a major concern for every country and thus establishing and developing renewable and alternative energy supply technologies and systems is a priority. Through covering both heating and electricity demands, combined heat and power (CHP) is one of the alternative energy efficient technologies [1] which has been established and developed with a major contribution in the energy production and supply scheme in various countries. CHP systems offer high operation flexibility and reliability with a simultaneous heat and power production and the possibility to be driven by alternative and renewable energy resources including solar thermal energy, biomass combustion heat and waste heat. A standard CHP system allows more rational use of energy resources and is capable of providing different products including hot water, space heating and electricity, with higher efficiency compared to conventional separate production systems [2]. The prime mover is the heart of the CHP system and the responsible for the simultaneous heat and electric power generation. In the recent decades, various prime movers have been considered for CHP applications including gas turbines, reciprocating engines, Stirling-based units, Rankine cycle-driven units and fuel cells. Despite the numerous advantages presented by CHP systems in terms of energy production and supply compared to separate energy production units, such systems have major drawbacks [3] including the dominance of large-scale CHP units and the limited number of micro-scale energy efficient CHP systems convenient for residential and building applications. Another disadvantage concerns the drop in the overall CHP system energy efficiency in the summer season when there is no need for heating and the cooling need is very high, making such system unfeasible and inappropriate in areas with hot and temperate climates. To overcome these challenges, a new concept of 'tri-generation' [4] was introduced in the recent years, coupling the standard CHP unit with a thermally-driven cooling/refrigeration technology, and thus delivering heating, electricity and cooling as energy products. A tri-generation system generally consists of five main components: prime mover, electricity generator, thermally-driven cooling unit, heat recovery unit and a management and control unit. A typical tri-generation system is presented in Figure 1, where the CHP unit is the heart of the system, with its standard operation and heat and electricity generation. In addition, excess heat generated in the form of flue gases or hot water is employed to drive the cooling technology using heat recovery units, and thus fulfilling the cooling demand. Compared to conventional separate energy production units, tri-generation systems allow various technical, environmental and socio-economic benefits [5] including higher energy production efficiency, lower operational and maintenance costs, less greenhouse gas emissions and higher energy supply reliability and security. Different cooling technologies could be used within the tri-generation system including absorption- and 
adsorption-based cooling, ejector cooling, liquid and solid desiccant cooling [6].

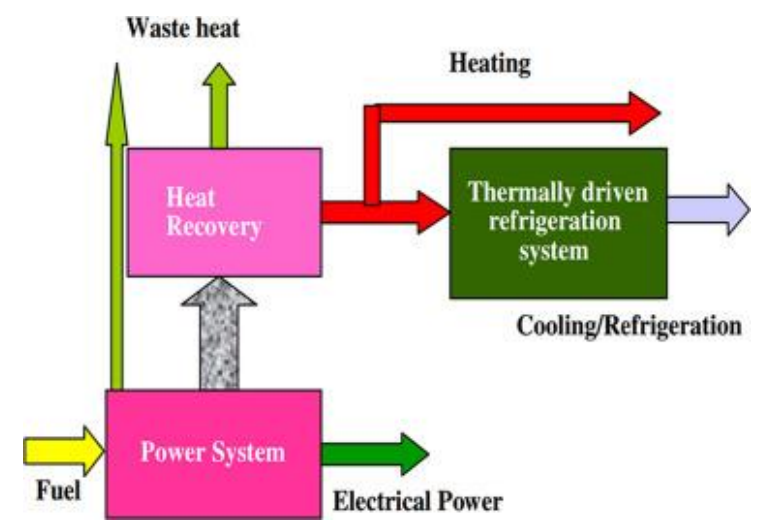

Figure 1. A typical tri-generation system.

For micro-scale tri-generation systems serving houses and residential buildings, Rankine- and Stirling-driven units are the two most favorable and feasible prime movers due to their reliable operation, low emissions, relatively high energy efficiencies and the capability to be integrated and driven by renewable energy resources. However, Stirling engines require relatively high-quality heat and is generally accompanied with high investment and operation costs. Thus, Rankine-based units provide an effective technology to fulfil heating and electricity demands of residential applications with an acceptable economic feasibility and energy efficiency. While the conventional water-based Rankine cycle-driven units have been used excessively in various applications in the last decades, such systems are associated with major problems [7] including the high risk of turbine blades erosion, high evaporator pressure and the excessive need for superheating to prevent condensation during the expansion phase. This in turn results into more expensive components, higher investment and operational costs and major safety concerns. Thus, organic Rankine cycle (ORC)-based systems [8,9], using organic working fluids instead of water, have been developed recently and received large interest with a growing block of research and investigations in various energy production and supply applications. Such systems allow eliminating the majority of the problems associated with water-based Rankine units mentioned above due to its relatively lower operating pressure and temperature, simple and compact design, costeffectiveness, high safety levels, low maintenance costs and high durability and reliability [10]. In addition, as organic fluids used in ORC units have lower boiling points compared to water, such units can easily be integrated and driven by low-grade waste heat and renewable resources including solar energy, biomass energy and geothermal heat. Regarding ORC working fluids, a wide range of fluids have been considered and investigated to serve ORC applications including the conventional, HFC and HCFC fluids which provide a cheaper option but with associated negative environmental impacts. A new class of HFE fluids was investigated by Tsai et al. [11] who carried out an environmental risk assessment of these fluids and stated that HEF fluids can be classified as environmentally friendly and can serve as a favorable substitute to HFC and HCFC fluids in the ORC systems including HFE 7000, HFE 7100, HFE 7200 and HFE 7500. This conclusion was supported by Liu et al. [12] and Qiu [13] who recommended the use of HFE 7000 and HFE 7100 for ORC applications.
In this study, an innovative micro-scale hybrid solarbiomass tri-generation system is presented and investigated to provide heating, cooling and electricity for residential applications. The prime mover of the proposed tri-generation system is an ORC-based combined heat and power unit allowing heating and electricity generation employing a micro-scale modified scroll-expander. In addition, an innovative integrated thermally-driven cooling system is employed comprising a liquid desiccant unit for air dehumidification and a dew point evaporative cooling unit with a cross flow heat and mass exchanger and a psychrometric energy core to provide the additional cooling effect. The proposed system is investigated and assessed to provide cooling, heating and electricity under Lebanese conditions. A complete technical, economic and environmental assessment of the micro-scale tri-generation system is performed to assess its applicability and feasibility.

\section{Proposed Tri-generation System Description}

An innovative hybrid biomass-solar-driven trigeneration system is proposed and investigated in this study to provide heating, cooling and electricity demands for a building application. The overall configuration of the combined cooling, heating and power generation system is presented in Figure 2. The proposed tri-generation system configuration comprises five main loops: 1) Heating Loop, 2) Organic Rankine Cycle Loop, 3) Condenser Loop, 4) Dehumidification Loop and 5) Cooling Loop. The trigeneration system consists of two major sub-systems: a) ORC-based combined heat and power unit and b) Liquid desiccant dehumidification and dew point cooling unit. Liquid desiccant dehumidification is one of the attractive alternative technologies for air dehumidification providing large savings on the primary energy consumption with an efficient and environmentally friendly operation mode compared to conventional vapor compression devices and cooling coils. The liquid desiccant dehumidification unit is coupled with an indirect evaporative cooling system as presented in Figure 2, where ambient air is introduced to the liquid desiccant unit first to be dehumidified and reduce its moisture content. In the second stage, the indirect evaporative cooling system is employed to further reduce the temperature of the dehumidified air without increasing its moisture content, providing better thermal comfort and indoor air quality in the air-conditioned space. The low temperature of regeneration associated with liquid desiccant units allows the utilization of renewable energy sources as biomass heat or solar energy to regenerate the weak desiccant and thus reducing energy consumption and gas emissions.

A totally renewable energy-based heating resource is employed to drive the overall tri-generation system, with a combination of a micro-scale biomass boiler and a smallscale parabolic solar concentrator. As solar energy is intermittent in nature with a fluctuating yield, employing such a combination of solar energy and biomass energy provides high flexibility and reliability in the heating supply to the system and provides a stability in the operation under a wide range of ambient conditions. To evaporate the ORC working fluid, hot water with at medium temperature (100$140^{\circ} \mathrm{C}$ ) is circulated at the ORC evaporator. In addition, water with a relatively low temperature $\left(60-80^{\circ} \mathrm{C}\right)$ is supplied at the liquid desiccant unit regenerator level to regenerate the weak liquid desiccant as presented in Figure 2 . 


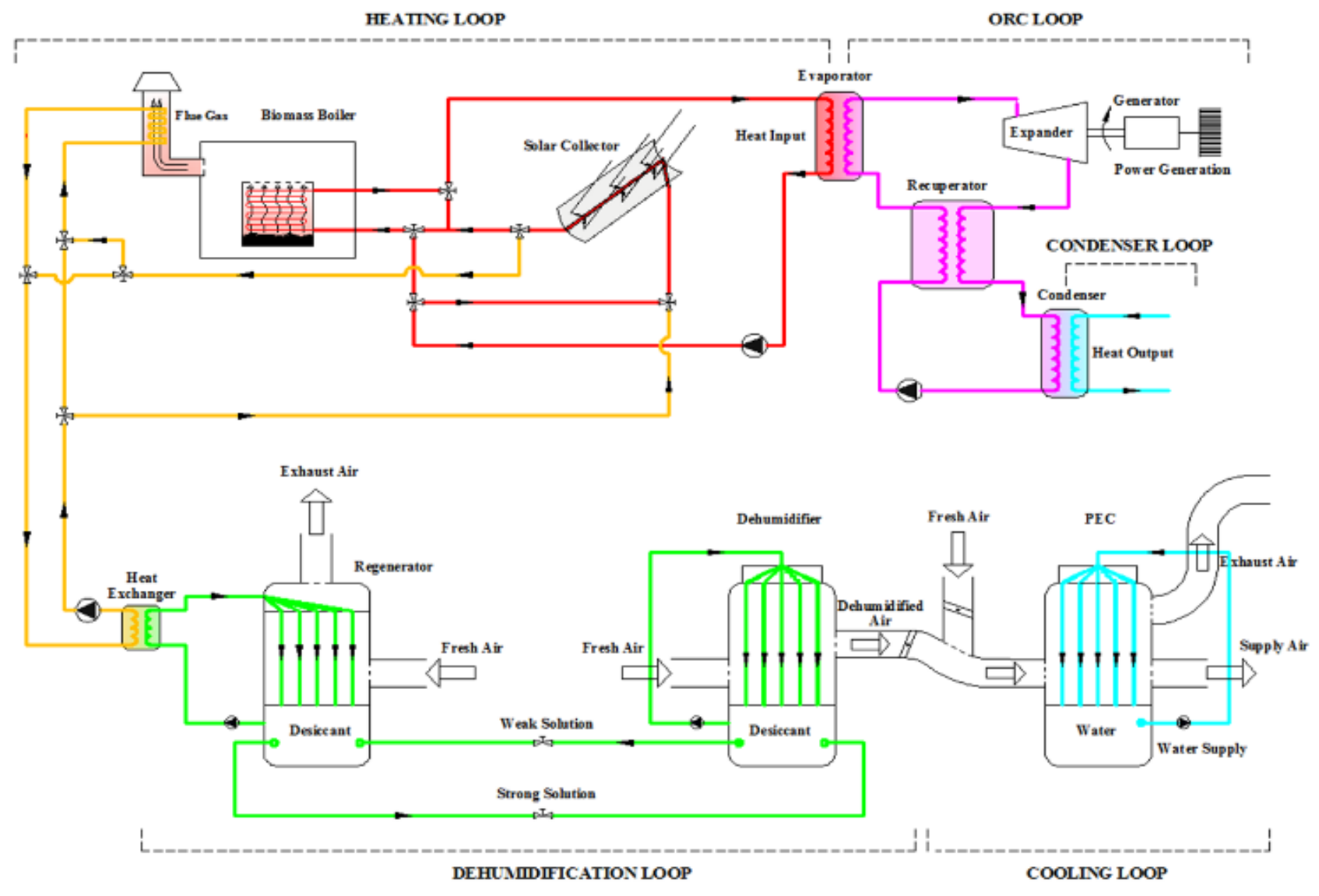

Figure 2. Overall configuration of the combined cooling, heating and power generation system.

In overall, the proposed tri-generation system can operate utilizing three different schemes in terms of the heating supply source:

- Solar generation only: The overall heat input to the trigeneration system is provided totally by the solar thermal collector where the biomass boiler is switched off.

- Biomass generation only: No heat input is delivered by the solar energy unit and the overall heat input to the trigeneration system is provided by the biomass boiler.

- Dual solar-biomass generation: The overall heat input to the tri-generation system is a combination of heat from the solar thermal collector and the biomass boiler which operate in series. Heat is provided first at the level of the solar collector depending on the level of solar irradiation available and on the ambient conditions, and thus additional heat input is provided at the level of the biomass boiler to fulfil the overall heat input needed for operation.

The proposed tri-generation system is capable of fulfilling heating and electricity needs through the organic Rankine cycle-based unit in addition to providing thermal comfort and conserving good indoor air quality through the integrated system of liquid desiccant dehumidification unit and the dew point evaporative cooling unit. Nevertheless, if cooling is not needed, the proposed tri-generation system can be employed only as a combined heat and power unit by disconnecting or switching off the liquid desiccant dehumidification and the dew point evaporative cooling units and thus the ORC unit will form the basis of the CHP system delivering heat and electric power. Utilizing and integrating the combined liquid desiccant-evaporative cooling unit with the ORC-CHP system allows widening the operation scope of the proposed system to serve various climatic conditions, different locations and different seasons over the whole year. In humid areas and when the air humidity is relatively high, humid ambient air is introduced to the liquid desiccant dehumidifier to be dehumidified and afterwards supplied to the evaporative cooling system to be further cooled down and generate the cooling effect. On the other hand, in dry areas or when the air humidity is relatively low, the dehumidification step is overlooked, and the ambient air is introduced directly to the evaporative cooling unit to be cooled, with no need to utilize the desiccant dehumidification system as shown in Figure 2. Thus, depending on the climatic conditions and the specific application, the tri-generation system will work under three different operation modes:

- Heating and Electricity (HE) mode: The system operates as a CHP system and the ORC unit is the only part running in the whole system to provide heat and electricity.

- Heating, Electricity and Cooling (HEC) mode: The ORC unit is running to provide heat and electricity, and the dew point cooling system is running to cool the relatively lowhumidity air.

- Heating, Electricity, Dehumidification and Cooling (HEDC) mode: All the units in the system are operating. The ORC unit is delivering heat and electricity and the liquid desiccant system is dehumidifying the air which is then supplied to the evaporative cooling unit to be further cooled down before being supplied to the building.

Figure 3 depicts the different energy flows within the proposed micro-scale hybrid solar-biomass tri-generation system. The heat input is provided by the solar collector aided by the biomass boiler to evaporate the working fluid in the ORC unit in addition to regenerating the weak liquid 


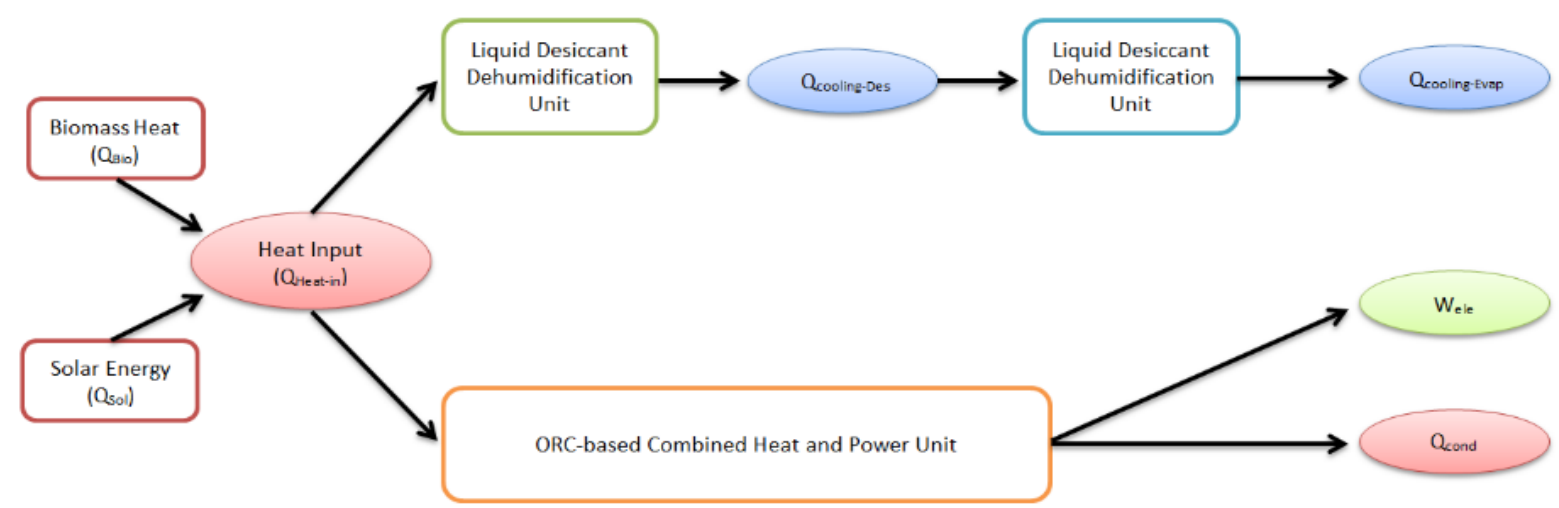

Figure 3. Energy flows within the micro-scale hybrid solar-biomass tri-generation system.

Table 2. Overall performance model of the hybrid tri-generation system.

\author{
ORC expander ideal work \\ Expander electric power output \\ Useful heat produced at the ORC condenser \\ Solar energy available at the solar collector \\ Biomass heat generated \\ Dew point cooler cooling capacity \\ Dehumidification unit cooling capacity \\ Overall cooling capacity \\ Total heat input to the tri-generation system
}

$$
\begin{gathered}
W_{E x}=\dot{m}_{O R C} \times\left(H_{E x, \text { in }}-H_{E x, \text { out }}\right) \\
W_{\text {ele }}=W_{E x} \times \eta_{\text {mech }} \times \eta_{\text {isentropic }} \\
Q_{\text {cond }}=\dot{m}_{\text {cond }} \times\left(H_{\text {cond,out }}-H_{\text {cond }, \text { in }}\right) \\
Q_{S o l}=I_{\text {Sol }} \times A_{\text {collector }} \\
Q_{\text {Bio }}=\dot{m}_{\text {Bio }} \times L H V \\
Q_{\text {cooling-Evap }}=\dot{m}_{\text {Evap }} \times\left(H_{\text {Evap,in }}-H_{\text {Evap }, \text { out }}\right) \\
Q_{\text {cooling-Des }}=\dot{m}_{\text {Des }} \times\left(H_{\text {Des, in }}-H_{\text {Des,out }}\right) \\
Q_{\text {cooling-overall }}=Q_{\text {cooling-Evap }}+Q_{\text {cooling-Des }} \\
Q_{\text {Heat-in }}=Q_{\text {Sol }}+Q_{\text {Bio }}
\end{gathered}
$$

desiccant in the dehumidification unit. Moreover, Table 1 presents the overall performance model of the combined cooling, heating and power generation system.

Regarding the system yield, the tri-generation system total energy production is characterized as the sum of the heating energy and electrical energy delivered by the ORCCHP unit and the overall cooling capacity produced by the combined liquid desiccant-evaporative cooling unit. On the other hand, the overall heat input required is defined as the heat supply to drive the CHP system in addition to the heat supply to regenerate the weak liquid desiccant. As a result, Eq. (1) below represents the holistic energy efficiency of the tri-generation system, being the ratio of the total energy production (heating, electricity and cooling) over the overall heat input required.

$\eta_{T r i}=\frac{Q_{\text {cond }} \times W_{\text {ele }} \times Q_{\text {cooling-Overall }}}{Q_{\text {Heat }- \text { in }}}$

where $Q_{\text {cond }}$ is the useful heat produced at the ORC condenser, $W_{\text {ele }}$ is the ORC expander electric power output $Q_{\text {cooling-Overall }}$ is the overall cooling capacity delivered by the combined dehumidification-cooling system and $Q_{\text {Heat-in }}$ is the total heat input to the trigeneration system.

\section{Proposed Tri-generation System Description}

Lebanon is located at the Eastern edge of the Mediterranean Sea with a narrow coastal strip of about 220 $\mathrm{km}$ long. It is characterized by a Mediterranean climate with long hot and dry summer and short, cold and rainy winter. Electricity is the major form of energy supply covering various Lebanese people needs including heating and cooling demands. However, the country is still suffering a yearly shortage of around $34 \%$ in the electric power supply where the residential and the commercial sector suffer daily power cuts and as a result tend to pay two electricity bills, one for the public electricity supply company and another for the backup private generators. Due to the lack of conventional fossil fuel energy resources, energy needs are majorly met through oil products import, with no effective harnessing of the potential renewable energy resources. Considering the high energy demand for cooling, heating and electricity and with more than 300 annual sunny days, the proposed innovative hybrid biomass-solar driven microscale tri-generation system would provide a viable solution to fulfil cooling, heating and electricity demands. In the sections below, a complete technical, economic and environmental assessment of the micro-scale tri-generation system is performed to assess its applicability and feasibility under Lebanese conditions.

Table 2. Parabolic solar collector specifications.

\begin{tabular}{lc}
\multicolumn{2}{c}{ Parabolic Solar Collector Characteristics } \\
\hline Collector length & $4 \mathrm{~m}$ \\
Collector width & $1.5 \mathrm{~m}$ \\
Glass mirror reflectivity & 0.9 \\
Absorber material & Stainless Steel \\
Absorber internal diameter & $0.025 \mathrm{~m}$ \\
Absorber external diameter & $0.028 \mathrm{~m}$ \\
Absorber absorptivity & 0.92 \\
Absorber emissivity & 0.1 \\
Glass cover internal diameter & 0.035 \\
Glass cover external diameter & 0.04 \\
Glass cover transmissivity & 0.92 \\
Glass cover emissivity & 0.9 \\
\hline
\end{tabular}

A $2 \mathrm{kWe}$ organic Rankine cycle-based combined heat and power system is utilized to provide the heating needs and electrical demands for a building application in Lebanon within the proposed tri-generation system. The ORC-based CHP could be employed as a standalone system for heat and electric power generation in winter months or as an integrated system with the dehumidification and cooling unit to provide cooling, heating and power needs in summer, where part of the heat provided by the CHP unit is utilized to 
regenerate the weak liquid desiccant in the dehumidification system. HFE7100 is employed as an organic working fluid in the ORC-CHP unit. A heating loop consisting of a $6 \mathrm{~m}^{2}$ parabolic solar collector and $15 \mathrm{~kW}$ wood pellets biomass boiler is employed to provide the heat input required to the tri-generation system. Depending on the solar irradiation available, heat input is provided first at the solar collector level and the additional heat required is fulfilled by the boiler. In the night time, the biomass boiler is responsible for providing the whole heat input needed. A parabolic solar thermal collector with an evacuated absorbing receiver line having a selective surface coating and anti-reflective coated glass cover envelope is considered for this case study. The specifications of the collector are presented in Table 2 .

In addition, Table 3 presents the Rankine cycle design parameters used for the ORC-CHP unit considered in addition to the geometrical specifications and the operational conditions of the cooler and dehumidifier heat and mass exchangers considered. The liquid desiccant employed is the Potassium formate solution (HCOOK) with a mass concentration of $74 \%$. The dehumidification-cooling system is designed to provide supply air with a dry bulb temperature less than $24^{\circ} \mathrm{C}$ and an average relative humidity of $55 \%$.

Table 3. Rankine cycle, dehumidification and cooling system design and operational parameters.

\begin{tabular}{lc}
\hline Parameter & Value \\
\hline Evaporator temperature $\left({ }^{\circ} \mathrm{C}\right)$ & 100 \\
Condenser temperature $\left({ }^{\circ} \mathrm{C}\right)$ & 25 \\
Pump efficiency & 0.8 \\
Expander mechanical efficiency & 0.8 \\
Biomass boiler efficiency & 0.9 \\
Pellets lower heating value $(\mathrm{kWh} / \mathrm{kg})$ & 4.8 \\
Dehumidifier channel length $(\mathrm{mm})$ & 500 \\
Dehumidifier channel height $(\mathrm{mm})$ & 5 \\
Cooler dry channel length $(\mathrm{mm})$ & 500 \\
Cooler wet channel length $(\mathrm{mm})$ & 500 \\
Cooler channel height $(\mathrm{mm})$ & 5 \\
Dehumidifier number of channels & 83 \\
Cooler number of dry channels & 55 \\
Supply air flow rate $\left(\mathrm{m}^{3} / \mathrm{h}\right)$ & 1000 \\
Cooler supply-to-intake air ratio $(\mathrm{m} / \mathrm{s})$ & $2 / 3$ \\
Supply air velocity $(\mathrm{m} / \mathrm{s})$ & 2 \\
&
\end{tabular}

\section{Tri-generation System Energy Performance}

The first step in the overall tri-generation system technical assessment is to calculate the yield from the solar thermal parabolic collector under real operational and climatic conditions in Lebanon. Utilizing ambient conditions data, the quasi-steady state model developed in [14] is employed to predict the available solar radiation and the optical and thermal performance of the solar collector for a typical day of each month all year round. The solar collector is considered to be implemented at an optimal tilt angle of $31.9^{\circ}$ [15], aiming to maximize the solar radiation falling on the inclined surface during the year seasons. Employing water mass flow rate of $0.01 \mathrm{~kg} / \mathrm{s}$, the hourly water outlet temperature from the parabolic solar collector for a typical day of each month is shown in Figure 4. It is shown that the supply water temperature could reach a maximum of $118^{\circ} \mathrm{C}$ in July and around $51^{\circ} \mathrm{C}$ in December. In addition, Figure 5 presents the daily total useful thermal energy delivered by the solar thermal collector for a typical day in each month. The month of July exhibits the maximum daily heat production of around $22.3 \mathrm{kWh}$, where the lowest thermal energy production is associated with January with a daily yield of around $6.7 \mathrm{kWh}$. The solar thermal collector is capable of delivering more than $10 \mathrm{kWh} /$ day of energy in the period from March to October where an average of 8 $\mathrm{kWh} /$ day is generated in the period from November to February.

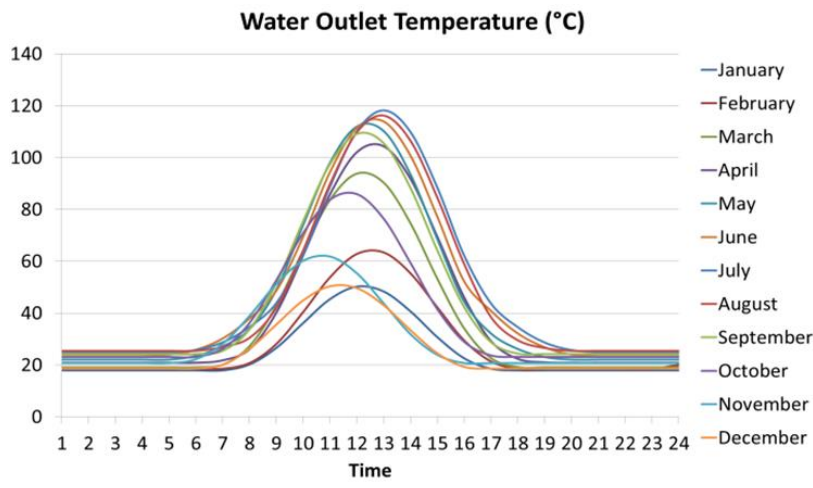

Figure 4. Supply water temperature from solar collector.

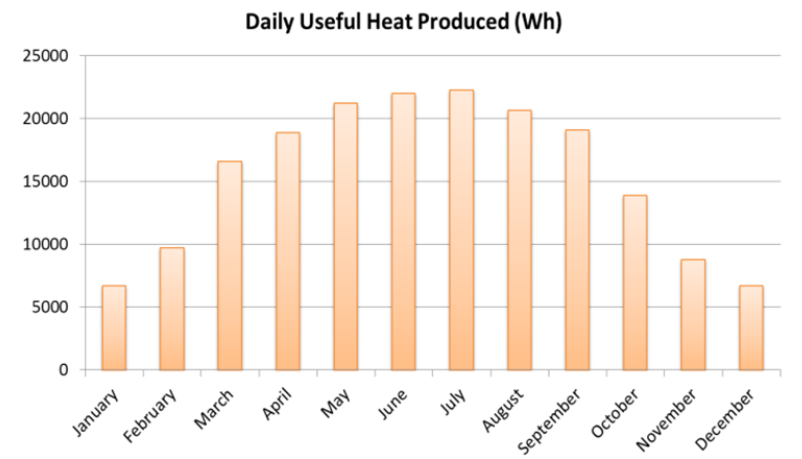

Figure 5. Daily solar thermal energy delivered.

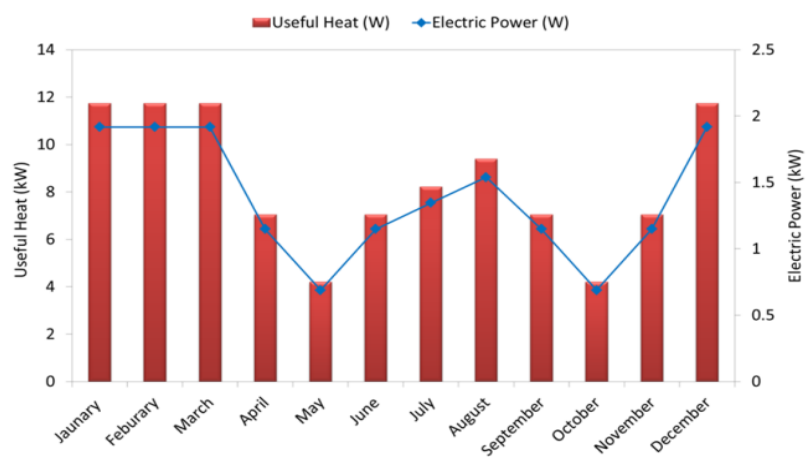

Figure 6. ORC-CHP system useful heat output and electricity generation in a typical day of each month.

The dynamic energy performance models developed by the authors [16,17], for the ORC-CHP system and the combined liquid desiccant dehumidification-evaporative cooling system, are employed to simulate the performance of the different tri-generation system subunits. Figure 6 presents the useful thermal energy delivered by the organic Rankine cycle-CHP unit in a typical day of each month. It is shown that the winter period extending from December to March exhibits the maximum useful heat output of around $11.75 \mathrm{~kW}$ where the minimum heat is produced in May and October with about $4.2 \mathrm{~kW}$ thermal energy delivered. In terms of electrical energy produced, Figure 6 also shows the variation in the electric power generation of the ORC-CHP unit in a typical day of each month, ranging between $0.7 \mathrm{~kW}$ and $1.92 \mathrm{~kW}$. As mentioned earlier, the heating supply scheme is that the heat input is provided first 
at the level of the solar thermal collector and the additional heat required is provided by the biomass boiler.

Moreover, Figure 7 shows the average solar energy share in the heat input to the tri-generation system in addition to the average ORC-CHP unit overall efficiency for a typical day of each month. Due to the superior thermal energy conversion efficiency of the biomass boiler compared to the solar collector, the simulations show that the overall CHP system efficiency is inversely proportional to the solar energy share in the heat input at the ORC evaporator and is proportional to the biomass boiler energy share. In overall, the CHP system efficiency ranges between $72 \%$ and $86 \%$, where the solar thermal energy share in the heat input ranges between $3.5 \%$ in January and 29\% in May.

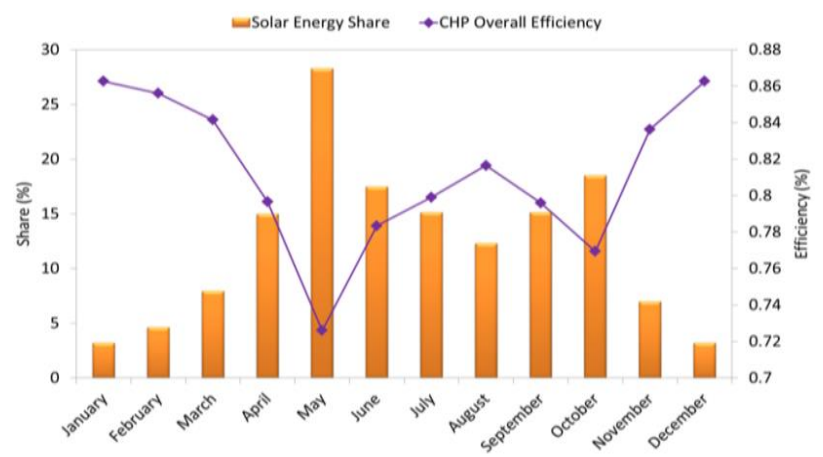

Figure 7. Average CHP efficiency and solar energy share in the tri-generation system heat input.

Considering ASHRAE Standard 55 regulation and the ambient air temperature and relative humidity data in Lebanon, it was assumed that the dehumidification and the cooling system is operating only in the months with an average daily ambient temperature exceeding $23^{\circ} \mathrm{C}$, meaning the period spanning from June until October. A comprehensive overview of the combined liquid desiccant dehumidification and evaporative cooling system operation is presented in Table 4, where both units are running from June to September, and only the evaporative cooling unit is operating in October, as the ambient air humidity ratio is acceptable. As shown in the table, the temperature of the air supply to the conditioned space from the cooler ranges between $21.3^{\circ} \mathrm{C}$ in June and $22.9^{\circ} \mathrm{C}$ in August, where the relative humidity of the air delivered by the cooler to the space is almost constant at an acceptable level of $55 \%$.

Table 4. Combined cooling system performance.

\begin{tabular}{lccccc}
\hline & Jun & Jul & Aug & Sep & Oct \\
$\mathrm{T}_{\text {ambient }}\left({ }^{\circ} \mathrm{C}\right)$ & 26.38 & 28.26 & 29.20 & 26.77 & 24.55 \\
$\mathrm{~T}_{\text {dehumidifier }}\left({ }^{\circ} \mathrm{C}\right)$ & 24.89 & 26.10 & 26.66 & 25.40 & --- \\
$\mathrm{T}_{\text {cooler }}\left({ }^{\circ} \mathrm{C}\right)$ & 21.31 & 22.38 & 22.95 & 21.95 & 22.44 \\
$\mathrm{RH}_{\text {ambient }}(\%)$ & 59.94 & 61.14 & 63.01 & 53.89 & 48.70 \\
$\mathrm{RH}_{\text {dehumidifier }}(\%)$ & 44.12 & 43.87 & 43.94 & 44.48 & --- \\
$\mathrm{RH}_{\text {cooler }}(\%)$ & 55.04 & 55.09 & 55.10 & 55.04 & 55.55 \\
$\mathrm{~W}_{\text {ambient }}\left(\mathrm{kg}_{\mathrm{H} 2 \mathrm{O}} / \mathrm{kg}_{\text {air }}\right)$ & 0.0128 & 0.0146 & 0.0160 & 0.0118 & 0.0093 \\
$\mathrm{~W}_{\text {cooler }}\left(\mathrm{kg}_{\mathrm{H} 2 \mathrm{O}} / \mathrm{kg}_{\text {air }}\right)$ & 0.0086 & 0.0092 & 0.0095 & 0.0090 & 0.0093 \\
\hline
\end{tabular}

As the employed thermally driven cooling sub-system within the tri-generation system comprises a liquid desiccant-based dehumidification unit and a dew point evaporative cooling unit where both units contribute to the cooling effect production, Figure 8 presents the share of each unit in the overall cooling capacity in each month. As the evaporative cooler is solely used in October, thus it contributes to $100 \%$ of the cooling capacity. In the other months, the evaporative cooler contribution ranges between $16 \%$ in August and $30 \%$ in September, where the dehumidification unit share is at its maximum of $84 \%$ in August and a minimum of $70 \%$ in September. It is shown that the liquid desiccant dehumidification unit contributes generally to the largest share of the overall cooling capacity due to the relatively high ambient air humidity ratio in the months from June to September and thus requiring high dehumidification effect to reduce the water vapor content and achieve thermal comfort. In addition, Figure 9 presents the monthly total energy delivered by the hybrid solarbiomass driven tri-generation system with a breakdown into cooling, heating and electrical energy generation. The maximum overall energy delivered by the tri-generation system ranges between 3.6 MWh in May and 10.1 MWh in December and January. The total energy delivered by the trigeneration system throughout the whole year is summed up to around 85.3 $\mathrm{MWh}$, in the form of heating, cooling and electrical energy.

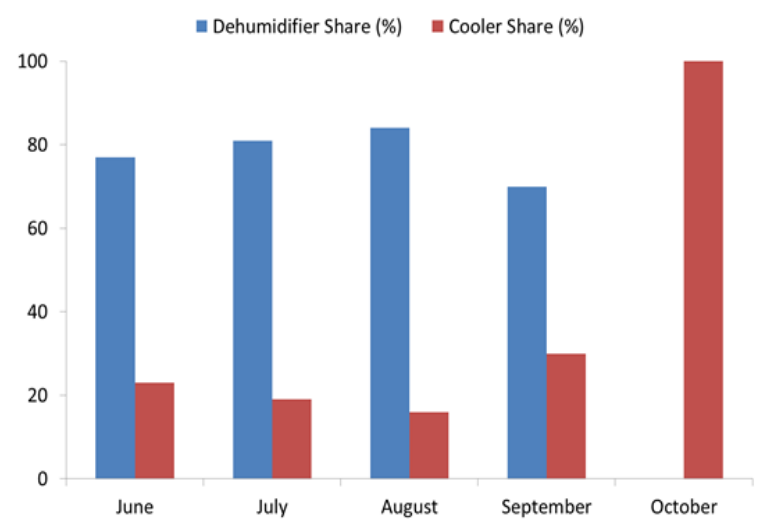

Figure 8. Dehumidifier and cooler share in the overall cooling capacity in each month.

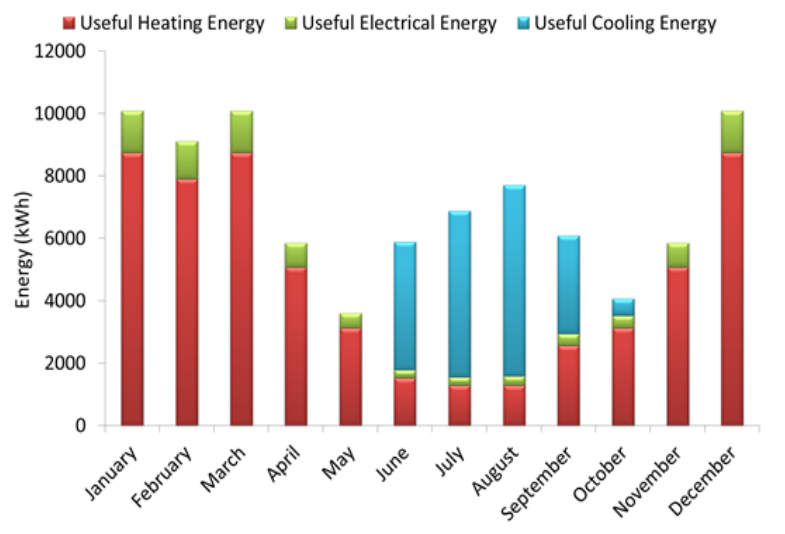

Figure 9. Tri-generation system monthly overall energy delivered.

\section{System Economic and Environmental Assessment}

Based on the technical assessment of the tri-generation energy performance in the previous section, an economic and environmental evaluation is presented in this section to assess the feasibility of using such system to provide cooling, heating and power demands for a building application under the Lebanese conditions. The majority of buildings in Lebanon rely on electrically-driven systems to supply both 
heating in winter and cooling in summer. Employing the proposed system will allow significant savings through making use of the solar and biomass energy to drive efficient and environmentally friendly heating, cooling and electric power generation technologies. Thus, we will be estimating the financial savings attained by the system compared to conventional electrically-driven cooling and heating systems and electric power supply from the grid. In terms of financial savings on the heating bill, the proposed system allows monthly savings ranging from 175 USD to a maximum of 1270 USD exhibited in December and January. In addition, the annual savings on the electricity bill accumulate to around 961 USD. Due to the implementation of the innovative cooling system, the savings on the cooling bill ranges from 15 USD in October to 311 USD in September. The total monthly savings on the energy bill due to the implementation of the proposed renewable energy-driven trigeneration system is shown in Figure 10 with a breakdown into heating energy savings, electricity energy savings and cooling energy savings. It is shown that the monthly savings attain a maximum of 1428 USD in December, January and March with a minimum of 436 USD in June. Moreover, the heating savings contribute to the largest share in the total bill savings. In overall, the annual financial savings due to the tri-generation system operation is around 8226 USD on the heating bill, 961 USD on the electricity bill and 951 USD on the cooling bill.

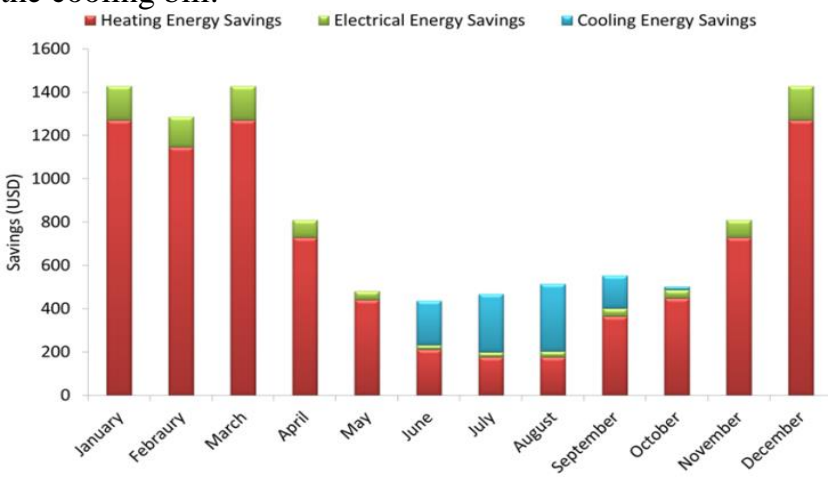

Figure 10. Overall monthly savings on the energy bill.

In addition, the cumulative system cost is estimated to be around 24000 USD, including the cost of different units and components, biomass boiler, solar collector and working fluids. Assuming 25 years as a system operation lifetime and wood pellets price of 300 USD/tonne, Figure 11 presents the Net Present Value of the tri-generation system at different interest rates. The NPV is estimated to be around 50579 USD at interest rate of $2 \%$ and decreasing to around 10624 USD at $10 \%$ interest rate. From the environmental perspective, to estimate the $\mathrm{CO}_{2}$ emissions avoided due to the tri-generation system operation, first the emissions due to burning the wood pellets in the biomass boiler shall be calculated. The maximum monthly $\mathrm{CO}_{2}$ emissions are attained in January with about $163 \mathrm{~kg}$ where May exhibits the lowest $\mathrm{CO}_{2}$ emissions with about $47 \mathrm{~kg}$. The overall annual $\mathrm{CO}_{2}$ emissions due to the biomass boiler operation are around $1296 \mathrm{~kg}$. Considering these emissions, the monthly net amount of $\mathrm{CO}_{2}$ emissions avoided due to the system operation is presented in Figure 12, ranging from 3.1 tonnes in June to 9.2 tonnes in March. In overall, the proposed solarbiomass driven tri-generation system allows an annual reduction of around 70.2 tonnes on $\mathrm{CO}_{2}$ emissions.

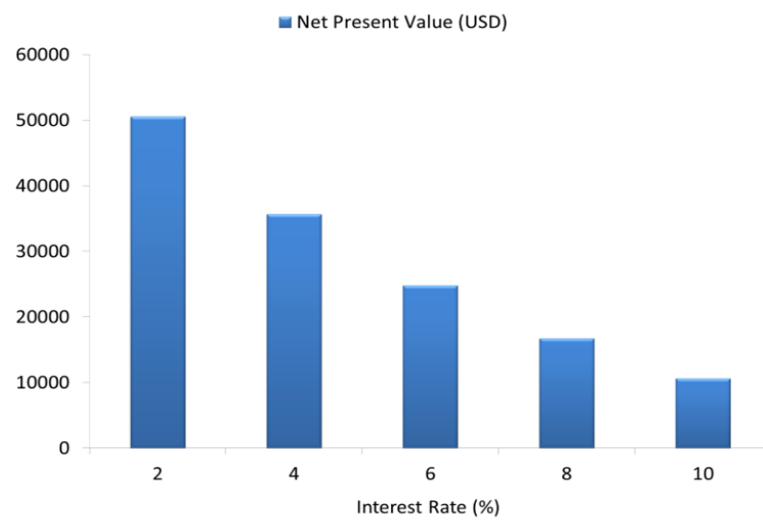

Figure 11. Tri-generation system net present value.

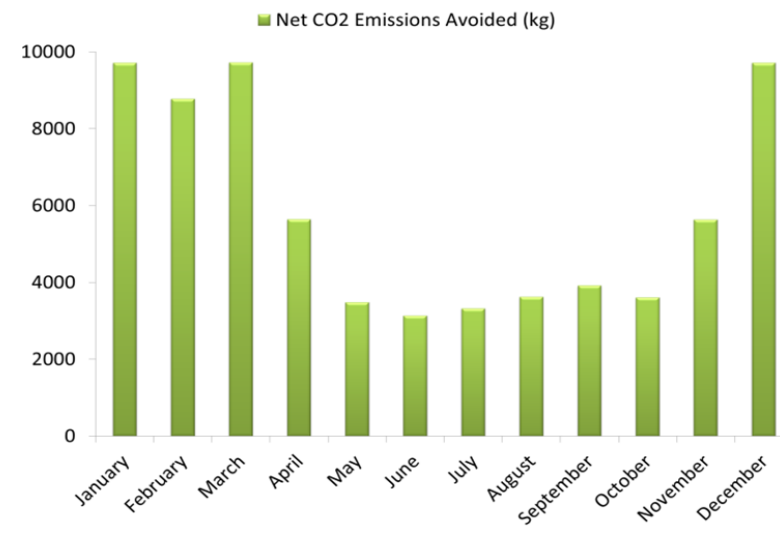

Figure 12. Net $\mathrm{CO}_{2}$ emissions avoided.

5. Conclusion

In this study, an innovative micro-scale tri-generation system is proposed to provide heating, cooling and electricity under Lebanese conditions. The tri-generation system runs solely on renewable energy resources with a hybrid system comprising a small-scale parabolic solar collector and a biomass boiler. The proposed system consists of two main sub-systems, an organic Rankine cycle-based combined heat and power system and a combined integrated liquid desiccant-evaporative cooling system. To investigate the feasibility and the applicability of such system under Lebanese conditions, an overall technical, economic and environmental assessment of the micro-scale tri-generation system performance is conducted and reported. A $2 \mathrm{kWe}$ ORC-based CHP unit with a micro-scale scroll expander is considered as the prime mover in the tri-generation system for heat and electricity generation, aided by a liquid desiccant dehumidification unit and a dew point evaporative cooling unit with a cross flow heat and mass exchanger and a psychrometric energy core to provide the additional cooling effect. The tri-generation system is driven by a hybrid heating system of a $6 \mathrm{~m}^{2}$ parabolic solar collector and a 15 $\mathrm{kW}$ wood pellet biomass boiler. It was shown that the total monthly tri-generation system delivered energy ranges from $3597 \mathrm{kWh}$ in May to $10089 \mathrm{kWh}$ in January with annual savings of around 8230 USD, 960 USD and 950 USD on the heating, electricity and cooling bills respectively. At an interest rate of $2 \%$, the system NPV was estimated at around 50500 USD, allowing an annual reduction of 70 tonnes on $\mathrm{CO}_{2}$ emissions. The overall technical, economic and environmental assessment carried out demonstrates the large potential of implementing such decentralized micro-scale 
renewable energy-driven tri-generation system under the Lebanese conditions in comparison to the separate production technologies.

\section{Nomenclature \\ $H \quad$ enthalpy, $\mathrm{J} / \mathrm{kg}$ \\ $\dot{m} \quad$ mass flow rate, $\mathrm{kg} / \mathrm{s}$ \\ $Q \quad$ heat, $\mathrm{W}$ \\ RH relative humidity, $\%$ \\ $T \quad$ temperature, ${ }^{\circ} \mathrm{C}$ \\ $w \quad$ humidity ratio, $\mathrm{kg}_{\mathrm{H} 2 \mathrm{O}} / \mathrm{kg}_{\text {air }}$ \\ W work, $\mathrm{W}$ \\ Greek symbols \\ $\eta \quad$ efficiency}

$\begin{array}{ll}\text { Subscripts and superscripts } \\ \text { Bio } & \text { biomass } \\ \text { cond } & \text { condenser } \\ \text { Des } & \text { desiccant } \\ \text { ele } & \text { electrical } \\ \text { Evap } & \text { evaporative cooler } \\ \text { Ex } & \text { expander } \\ \text { in } & \text { inlet } \\ \text { out } & \text { outlet } \\ \text { Sol } & \text { solar }\end{array}$

\section{References}

[1] S. Martinez, G. Michaux, P. Salagnac, J.L. Bouvier, "Micro-combined heat and power systems (microCHP) based on renewable energy sources," Energy. Convers. Manage., 154, 262-285, 2017.

[2] S. Murugan, B. Horák, "A review of micro combined heat and power systems for residential applications," Renew. Sust. Energ. Rev., 64, 144-162, 2016.

[3] A. Khaliq, "Exergy analysis of gas turbine trigeneration system for combined production of power heat and refrigeration,” Int. J. Refrig. 32, 534-545, 2009.

[4] H.A. Moussawi, F. Fardoun, H. Louahlia, "Selection based on differences between cogeneration and trigeneration in various prime mover technologies," Renew. Sust. Energ. Rev., 74, 491-511, 2017.

[5] Cogeneration \& Trigeneration - How to Produce Energy Efficiently, Internationale Zusammenarbeit (GIZ) GmbH. [Online]. Available: https://www.giz.de/expertise/downloads/giz2016-enenergy-cogeneration-trigeneration-guide.pdf (accessed Sep. 19, 2018).
[6] D. Sonar, S.L. Soni, D. Sharma, "Micro-trigeneration for energy sustainability: Technologies, tools and trends," Appl. Therm. Eng. 71(2), 790-796, 2014.

[7] B.F. Tchanche, G. Lambrinos, A. Frangoudakis, G. Papadakis, "Low-grade heat conversion into power using organic Rankine cycles - A review of various applications," Renew. Sust. Energ. Rev. 15, 3963-3979, 2011.

[8] K. Rahbar, S. Mahmoud, R.K. Al-Dadah, N. Moazami, S.A. Mirhadizadeh, "Review of organic Rankine cycle for small-scale applications," Energ. Convers. Manage. 134, 135-155, 2017.

[9] V.L. Le, S. Declaye, X. Dumas, L. Ferrand, V. Lemort, "Waste heat recovery by means of Organic Rankine Cycle (ORC) system coupled with two-phase closed thermosyphons," Int. J. of Thermo., 20, 81-89, 2017.

[10] D. Micheli, M. Reini, R. Taccani, "Multiple Expansion ORC for Small Scale - Low Temperature Heat Recovery," Int. J. of Thermo., 21, 62-68, 2018.

[11] W.T. Tsai, "Environmental risk assessment of hydrofluoroethers (HFEs)," J. Hazard. Mater. 119, 69$78,2005$.

[12] H. Liu, Y. Shao, J. Li, “A biomass-fired micro-scale CHP system with organic Rankine cycle (ORC) Thermodynamic modelling studies," Biomass Bioenergy 35, 3985-3994, 2011.

[13] G. Qiu, "Selection of working fluids for micro-CHP systems with ORC," Renew. Energ. 48, 565-570, 2012.

[14] M. Jradi, S. Riffat, "Year-round numerical simulation of a parabolic solar collector under Lebanese conditions: Beirut case study," Int. J. Ambient Energy 35, 164-179, 2014.

[15] H. Darhmaoui, D. Lahjouji, "Latitude Based Model for Tilt Angle Optimization for Solar Collectors in the Mediterranean Region," Energy Procedia 42, 426-435, 2013.

[16] M. Jradi, S. Riffat, "Experimental investigation of a biomass-fuelled micro-scale tri-generation system with an organic Rankine cycle and liquid desiccant cooling unit," Energy 71, 80-93, 2014.

[17] M. Jradi, S. Riffat, "Energy performance of an innovative liquid desiccant dehumidification system with a counter-flow heat and mass exchanger using potassium formate," Renew. Bioresour. 2, 1-11, 2014. 